\title{
The role of average atomic volume in predicting negative thermal expansion: The case of $\operatorname{REFe}(\mathrm{CN})_{6}$
}

\author{
Qilong Gao ${ }^{1 *}$, Qiang Sun ${ }^{1}$, Alessandro Venier ${ }^{3}$, Andrea Sanson $^{3}$, Qingzhen Huang ${ }^{4}, \mathrm{Yu} \mathrm{Jia}^{5,1}$, \\ Erjun liang ${ }^{1}$ and Jun Chen ${ }^{2 *}$
}

Negative thermal expansion (NTE), as an abnormal physical behavior, has been followed by scientists' attention over the past 30 years, due to its fascinating physical mechanisms and the prospect of high-precision thermal expansion control [1-5]. Although some NTE materials (alloys [6], cyanides [7], fluorides [8-10], nitrides [11], oxides [12,13], MOFs [14-16], etc.) have been found, their number and variety are still very small, limiting their applications. Exploring and designing new NTE materials is an important and challenging topic for the development of the field of NTE. Researchers have been continually reviewing and summarizing obtained results to look to the future of NTE [17-23]. It is known that the NTE behavior in open-framework materials is related to the low-frequency phonons, while the NTE behavior in functional materials with magnetic or electronic transitions comes from the electronic structure, but it is still difficult for us to find new NTE materials. Interestingly, there has been some studies which tried to construct new NTE materials, for example fabricating microstructures in $\mathrm{Ca}_{2} \mathrm{RuO}_{4}$ systems to achieve colossal NTE [24], designing three-dimensional metamaterials to tailor the thermal expansion from negative to positive continuously [25] or exploiting the nanosizing effect in $\mathrm{Au}$ [26] or $\mathrm{CuO}$ [27] to obtain the NTE, even super NTE behavior. Hence, it is strongly necessary to develop or introduce new ways to explore NTE materials.

Recently, Gao et al. [28] proposed a new concept of average atomic volume (AAV) by summarizing the structural characteristics of isotropic framework NTE materials and successfully discovered the NTE material $\operatorname{AgB}(\mathrm{CN})_{4}$. The concept of $\mathrm{AAV}$ is a simple parameter to indicate the average volume of atoms in a unit cell. In other words, it means that the unit volume is divided by the atom number in a lattice cell. The formula is $\mathrm{AAV}=V /(Z \times N)$, where $V$ is the unit cell volume, $Z$ is the cell formula units, and $N$ is the number of atoms in the chemical formula. Here, with the help of AAV, one could evaluate the thermal expansion behavior [28]. It should be noted that the number of anisotropic materials is much larger than that of isotropic ones. If we extend this concept to anisotropic materials, it will be possible to seek much more potential NTE materials. Due to their flexible networking architecture, many cyanides/Prussian blue analogues (PBAs), such as $\mathrm{Zn}(\mathrm{CN})_{2}$ [29], $\mathrm{ZnPt}(\mathrm{CN})_{6}[30], \mathrm{LaCo}(\mathrm{CN})_{6}[31]$ and $\mathrm{ScCo}(\mathrm{CN})_{6}$ [32], display a fascinating NTE behavior. Gao et al. [33] reported the large NTE behavior in $\mathrm{YFe}(\mathrm{CN})_{6}$, whose $\mathrm{AAV}$ is $22.58 \AA^{3}$, well above the critical point (assessed to $\sim 16 \AA^{3}$ by Gao et al. [28]). The framework structure of isostructural materials with formula $R E F e(\mathrm{CN})_{6}$ consists of $R E \mathrm{~N}_{6}$ trigonal prisms alternating with $\mathrm{FeC}_{6}$ octahedra, as shown in Fig. 1a. The values of AAV for $R E F e(C N)_{6}$ materials range from $22 \AA^{3}\left(\mathrm{LuFe}(\mathrm{CN})_{6}\right)$ to $24.7 \AA^{3}$ $\left(\mathrm{LaFe}(\mathrm{CN})_{6}\right)$, much larger than $16 \AA^{3}$. It seems natural to us to ask whether the $R E F e(C N)_{6}$ shows NTE behavior. Interestingly, the intrinsic thermal expansions of $R E F e(C N)_{6}(R E=\mathrm{La}, \mathrm{Sm}$, $\mathrm{Ho}, \mathrm{Lu})$, which were determined by synchrotron X-ray diffraction (SXRD) at Advanced Photon Source (APS) (Fig. 1b), show larger volume NTE behavior in the temperature range of 100 $525 \mathrm{~K}$ than expected. One can clearly see that the negative coefficient of thermal expansion (CTE) has a linear relationship with the AAV, thus providing a way to predict the CTE of similar systems and also showing that they have similar NTE mechanism.

In order to investigate the NTE mechanism of $R E F e(C N)_{6}$, we selected two representative NTE materials, $\mathrm{LaFe}(\mathrm{CN})_{6}$ (strong $\mathrm{NTE}$ ) and $\mathrm{LuFe}(\mathrm{CN})_{6}$, to be studied from the lattice and local structure perspectives. Here, we combined temperature-dependent neutron powder diffraction (NPD) and extended X-ray absorption fine structure (EXAFS) data to extract information regarding thermal vibrations. The anisotropic atomic displacement parameter (ADP) is an important parameter to reflect the structural properties of crystals. Under the temperature field, the ADP could display the thermal ellipsoids of atoms, which reflects the information of thermal vibrations [34]. Here, the shape and size of displacement ellipsoids of the bridge $\mathrm{CN}$ atoms were extracted to reveal the vibrational information in the required directions. As shown in Fig. $2 \mathrm{a}, \mathrm{b}$, the bridge $\mathrm{CN}$ atoms show large anisotropy (the values of transverse ADPs in $\mathrm{LaFe}(\mathrm{CN})_{6}$ (strong $\mathrm{NTE}$ ) and $\mathrm{LuFe}(\mathrm{CN})_{6}$ are many times larger than the longitudinal ones). As for other PBAs, the transverse ADPs of $\mathrm{N}$ atoms are much larger than those of $\mathrm{C}$ atoms. This

\footnotetext{
${ }^{1}$ Key Laboratory of Materials Physics of Ministry of Education, and School of Physics and Microelectronics, Zhengzhou University, Zhengzhou 450052, China

${ }^{2}$ Beijing Advanced Innovation Center for Materials Genome Engineering, School of Mathematics and Physics, Department of Physical Chemistry, University of Science and Technology Beijing, Beijing 100083, China

${ }^{3}$ Department of Physics and Astronomy, University of Padova, Padova I-35131, Italy

${ }^{4}$ NIST Center for Neutron Research, National Institute of Standards and Technology, Gaithersburg MD, 20899-6102, United States

${ }^{5}$ Key Laboratory of Special Functional Materials of Ministry of Education of China, and School of Materials Science and Engineering, Henan University, Kaifeng 475004, China

* Corresponding authors (emails: qilonggao@zzu.edu.cn (Gao Q); junchen@ustb.edu.cn (Chen J))
} 

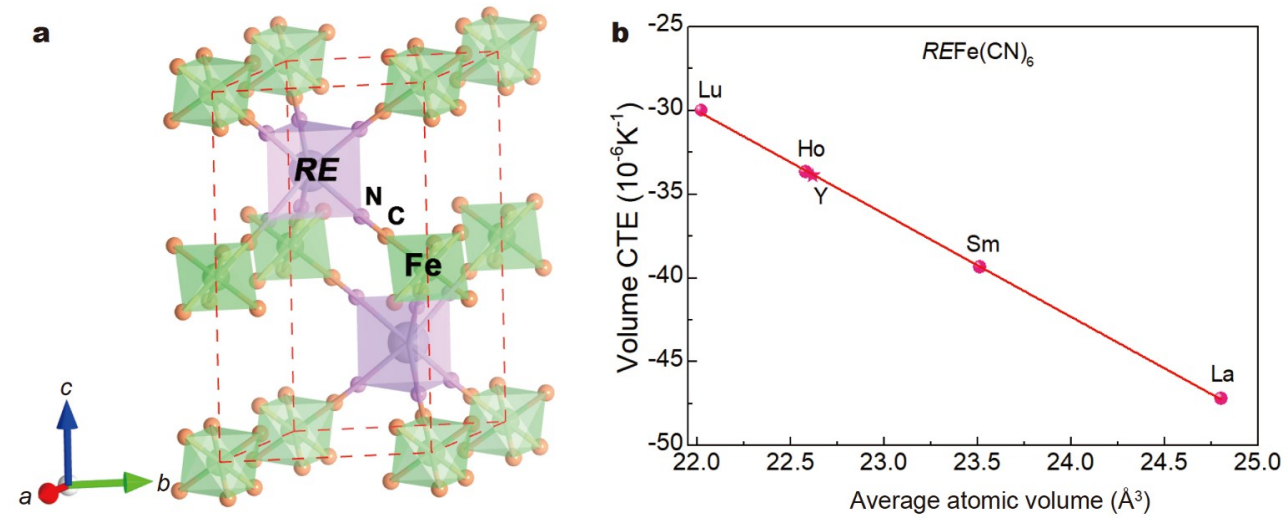

Figure 1 (a) The structure of $R E \mathrm{Fe}(\mathrm{CN})_{6}(R E=\mathrm{La}, \mathrm{Sm}, \mathrm{Ho}, \mathrm{Lu})$, possessing hexagonal symmetry $\left(P 6_{3} / m m c\right)$ owing to the combination of $R E \mathrm{~N}_{6}$ trigonal prisms alternating with $\mathrm{FeC}_{6}$ octahedra; (b) the linear relationship between the volume CTE (experimental values from SXRD) and AAV for $R E F e(C N)_{6}$.
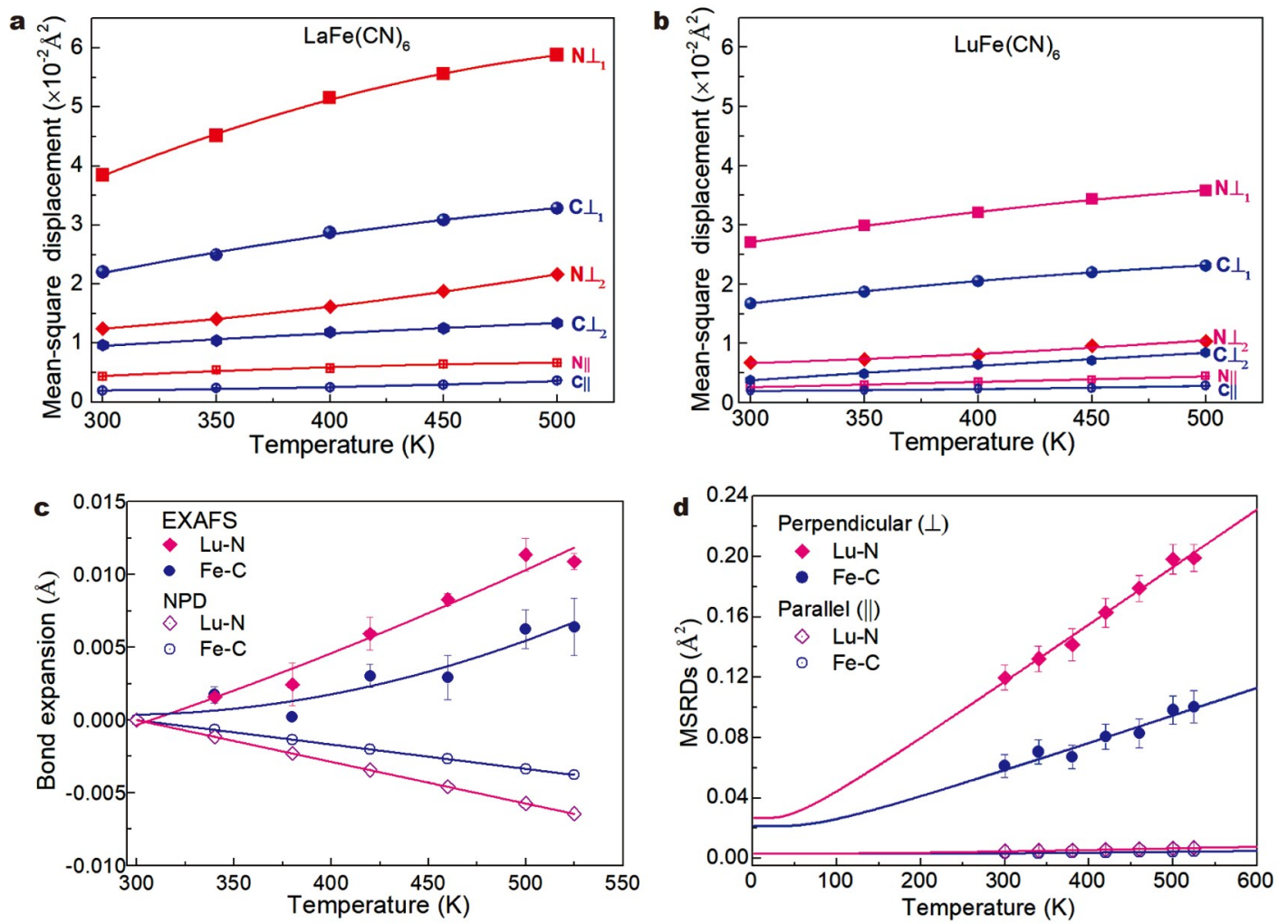

Figure 2 The thermal vibrational information of $R E F e(C N)_{6}$. Temperature dependence of ADPs of the $\mathrm{N}$ and $\mathrm{C}$ atoms derived from $\mathrm{NPD}$ in (a) $\mathrm{LaFe}(\mathrm{CN})_{6}$ and (b) $\mathrm{LuFe}(\mathrm{CN})_{6}$. (c) The true and apparent $\mathrm{Lu}-\mathrm{N}$ and $\mathrm{Fe}-\mathrm{C}$ bond lengths extracted, respectively, from EXAFS and NPD, (d) perpendicular $(\perp)$ and parallel (II) MSRDs of $\mathrm{Lu}-\mathrm{N}$ and $\mathrm{Fe}-\mathrm{C}$ bonds in $\mathrm{LuFe}(\mathrm{CN})_{6}$.

also suggests that the transverse thermal vibration of $\mathrm{N}$ and $\mathrm{C}$ atoms is the driving force for NTE in $R E F e(C N)_{6}$. Compared with the value of ADPs between $\mathrm{LaFe}(\mathrm{CN})_{6}$ (strong NTE) and $\mathrm{LuFe}(\mathrm{CN})_{6}$, the transverse ADPs of $\mathrm{CN}$ atoms in strong NTE $\mathrm{LaFe}(\mathrm{CN})_{6}$ are much larger than those in $\operatorname{LuFe}(\mathrm{CN})_{6}$ (the detailed information of NPD structure refinements of $\mathrm{LaFe}(\mathrm{CN})_{6}$ and $\mathrm{LuFe}(\mathrm{CN})_{6}$ is shown in Fig. S1, Tables S1 and S2). This directly indicated the relevant difference between $\mathrm{LaFe}(\mathrm{CN})_{6}$ (strong $\mathrm{NTE}$ ) and $\mathrm{LuFe}(\mathrm{CN})_{6}$ and also suggested that in same NTE systems with open-framework structure the larger the AAV, the larger the transverse ADPs of bridge atoms, and thus a stronger NTE. To further illustrate the local structure vibrational information, we conducted the EXAFS experiment with variable temperature. Due to the energy of La L3-edge and Fe K-edge having partial overlapping, we collected only the EXAFS data of $\mathrm{LuFe}(\mathrm{CN})_{6}$ (the detail experiments and data analysis information please see Figs S2-S5, Tables S3 and S4). Here, we adopted NPD measurements to extract the "apparent" bond lengths of $\mathrm{Lu}-\mathrm{N}$ and $\mathrm{Fe}-\mathrm{C}$ in $\mathrm{LuFe}(\mathrm{CN})_{6}$ (Fig. 2c), which display contraction. The "true" bond lengths of $\mathrm{Lu}-\mathrm{N}$ and $\mathrm{Fe}-\mathrm{C}$, which interestingly show PTE behavior, were determined from EXAFS (Fig. 2c). Such opposite thermal expansion behavior through similar experimental measurements is also observed in other NTE materials such as $\mathrm{ZrW}_{2} \mathrm{O}_{8}$ [35], $\mathrm{TiCo}(\mathrm{CN})_{6}[36]$ and 
$\mathrm{Cu}_{2} \mathrm{P}_{2} \mathrm{O}_{7}$ [37]. In order to further study the thermal vibrations, we also extracted the atomic mean square relative displacements (MSRDs) [38] of $\mathrm{Lu}-\mathrm{N}$ and $\mathrm{Fe}-\mathrm{C}$ atomic pairs. The temperature dependence of $\mathrm{Lu}-\mathrm{N}$ and $\mathrm{Fe}-\mathrm{C}$ MSRDs shows that the perpendicular ones are both much larger than the parallel ones (Fig. 2d). As shown in Fig. S5, the anisotropy of thermal vibrations of $\mathrm{Lu}-\mathrm{N}$ is much larger than that of the $\mathrm{Fe}-\mathrm{C}$ ones. This indicates that the contribution to the NTE behavior of $\mathrm{LuFe}(\mathrm{CN})_{6}$ mainly originates from the $\mathrm{Lu}-\mathrm{N}$ atom pairs, which is in good agreement with the result of ADPs.

To further investigate the NTE mechanism and reveal the reason for the differences in NTE among the $R E F e(C N)_{6}$ system, we selected $\mathrm{LaFe}(\mathrm{CN})_{6}$ (strong NTE) and $\mathrm{LuFe}(\mathrm{CN})_{6}$ as representative samples to obtain further lattice dynamics information by density functional theory (DFT) calculations. As shown in Fig. $3 \mathrm{a}, \mathrm{b}$, the phonon dispersion of $\mathrm{C}$ and $\mathrm{N}$ atoms shows that the vibrations of $\mathrm{N}$ atoms play a leading role below $200 \mathrm{~cm}^{-1}$, and most vibrational modes in the low-frequency region have negative Grüneisen parameters (Fig. $3 c$, d). This indicates that the NTE driving force of $R E F e(C N)_{6}$ is the thermal vibration of $\mathrm{C}$ and $\mathrm{N}$ atoms in low-frequency modes. The insets in Fig. $3 \mathrm{c}, \mathrm{d}$ show vibrational mode with the same transverse direction for $\mathrm{N}$ and $\mathrm{C}$ atoms, which has the largest negative Grüneisen parameters. These results also confirmed that the mode with the same transverse vibration direction for $\mathrm{C}$ and $\mathrm{N}$ atoms gives a contribution to NTE greater than the other modes in the PBA NTE system of materials. Interestingly, the frequency of this mode in the strong-NTE material $\mathrm{LaFe}(\mathrm{CN})_{6}$ is $49 \mathrm{~cm}^{-1}$, which is lower than in the case of the NTE material $\operatorname{LuFe}(\mathrm{CN})_{6}\left(53 \mathrm{~cm}^{-1}\right)$.
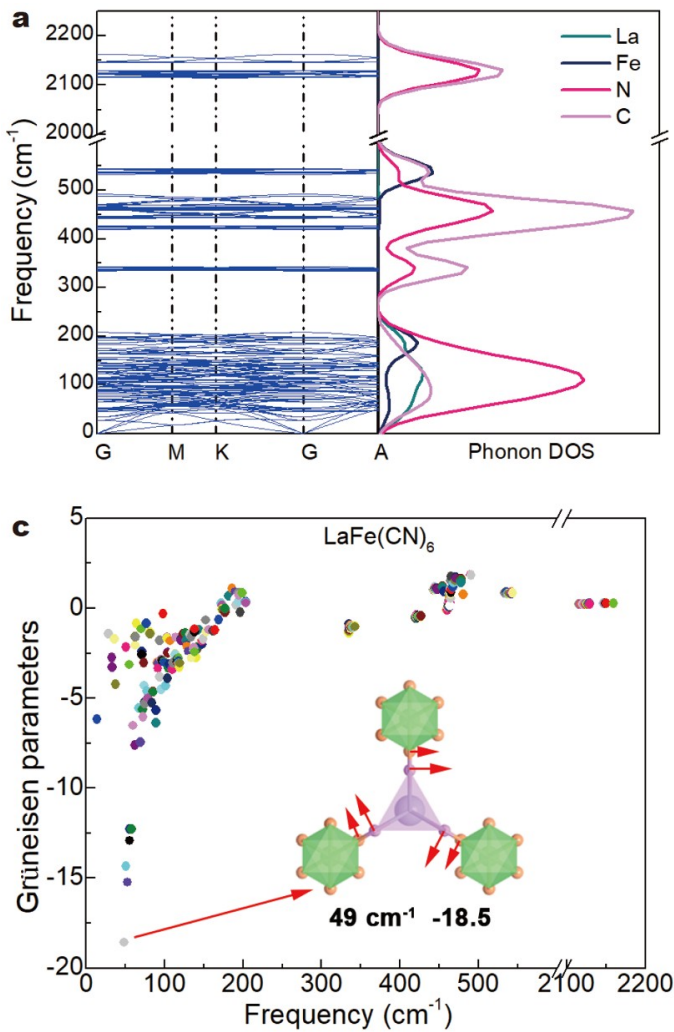

Moreover, it should be noted that the number of low-frequency modes with negative Grüneisen parameters $(\leq-5)$ for the strong$\mathrm{NTE} \mathrm{LaFe}(\mathrm{CN})_{6}$ is greater than that for $\mathrm{LuFe}(\mathrm{CN})_{6}$. These results confirm that the frequency and negative Grüneisen parameter of the thermal vibrations are the factors relevant to the difference in NTE behaviors in the $R E F e(C N)_{6}$ system.

Back to the concept of AAV, the discovery of NTE in the $R E F e(\mathrm{CN})_{6}$ system suggested that it is applicable to anisotropic materials. As shown in Fig. 4, it covers most classical NTE openframework materials among oxides, fluorides, cyanides and PBAs (Table S5). One can clearly see that there seems to be a strong correlation between CTE and AAV, especially for the same type of materials. As the value of AAV increases, NTE enhances (Fig. 4). This is also corroborated by the relationship between thermal expansion and the length of the lattice parameter observed in Ref. [39]. In the case of $R E F e(C N)_{6}$, the larger the AAV, the larger the transverse ADPs of $\mathrm{CN}$ atoms, and thus a much stronger NTE appears. The DFT results for $R E F e(C N)_{6}$ indicated that the larger the AAV, the lower the frequency and the larger the value of negative Grüneisen parameter for the NTE contributing phonon modes. Hence, it not only provides one possible way to predict thermal expansion in inorganic open-framework materials, but also brings new insight into the design of super NTE materials, thus promoting further developments of NTE.

In summary, we have introduced the concept of AAV to predict the NTE of materials in the $R E F e(C N)_{6}$ system. A combined study of NPD, EXAFS and DFT results was performed to reveal the mechanism of thermal expansion. The $R E F e(C N)_{6}$
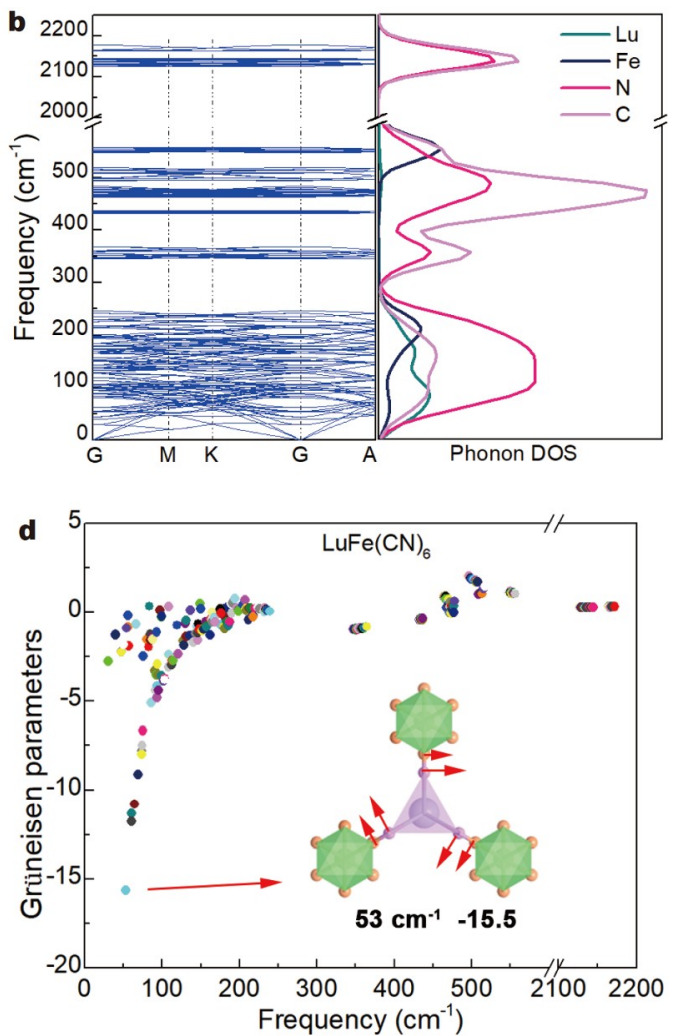

Figure 3 The results of DFT calculations. Phonon dispersion curves and phonon DOS for (a) $\mathrm{LaFe}(\mathrm{CN})_{6}$ and $(\mathrm{b}) \mathrm{LuFe}(\mathrm{CN})_{6}$. The mode $\mathrm{Grüneisen}$ parameters as a function of vibrational frequency for $(\mathrm{c}) \mathrm{LaFe}(\mathrm{CN})_{6}$ and $(\mathrm{d}) \mathrm{LuFe}(\mathrm{CN})_{6}$. Insets: the transverse vibrational modes with the same direction of vibration for $\mathrm{N}$ and $\mathrm{C}$ atoms showing the largest negative Grüneisen parameters at the low frequencies of $49 \mathrm{~cm}^{-1}\left(\mathrm{LaFe}(\mathrm{CN})_{6}\right)$ and $53 \mathrm{~cm}^{-1}\left(\mathrm{LuFe}(\mathrm{CN})_{6}\right)$. The direction and size of arrows reflect the directions and amplitudes of vibrations of $\mathrm{N}$ and $\mathrm{C}$ atoms. 


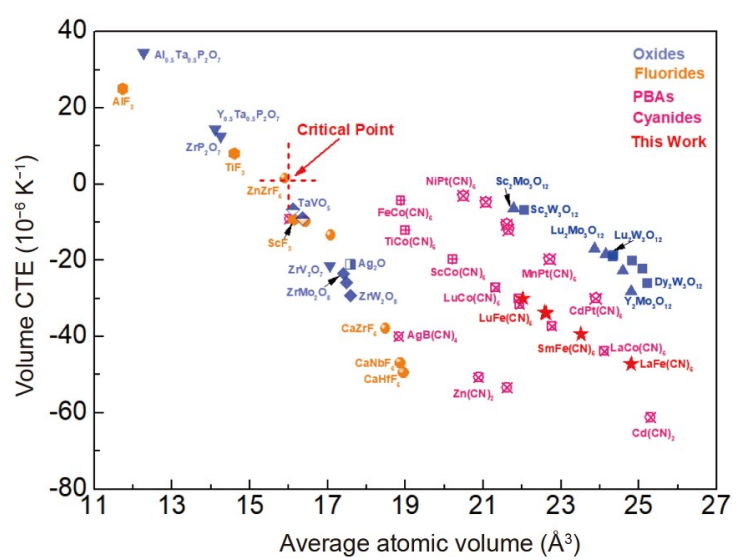

Figure 4 The strong relationships between thermal expansion and the AAV of open-framework fluorides, oxides and PBAs.

system has large NTE behavior in the temperature range of 100$525 \mathrm{~K}$. The ADPs and MSRDs resulting from the analysis clearly indicated that the NTE of the $R E F e(C N)_{6}$ system is determined by the transverse thermal vibrations of $\mathrm{CN}$ groups, which is also reflected in the low-frequency phonon modes with negative Grüneisen parameters. This work not only reported new NTE materials with chemical formula $R E F e(C N)_{6}$, but also gave us some insight into the prediction of NTE behavior for most framework materials, such as oxides, fluorides, PBAs and many others.

Received 21 August 2021; accepted 14 September 2021; published online 19 October 2021

1 Mary TA, Evans JSO, Vogt T, et al. Negative thermal expansion from 0.3 to 1050 Kelvin in $\mathrm{ZrW}_{2} \mathrm{O}_{8}$. Science, 1996, 272: 90-92

2 Attfield JP. A fresh twist on shrinking materials. Nature, 2011, 480: 465-466

3 Zhang Y, Chen B, Guan D, et al. Thermal-expansion offset for highperformance fuel cell cathodes. Nature, 2021, 591: 246-251

4 Yang Y, Lin Z, Li R, et al. Thermal expansion coefficient of monolayer $\mathrm{MoS}_{2}$ determined using temperature-dependent Raman spectroscopy combined with finite element simulations. Microstructures, 2021, doi: 10.20517/microstructures.2021.02

5 Chen J, Hu L, Deng J, et al. Negative thermal expansion in functional materials: Controllable thermal expansion by chemical modifications. Chem Soc Rev, 2015, 44: 3522-3567

6 Song Y, Shi N, Deng S, et al. Negative thermal expansion in magnetic materials. Prog Mater Sci, 2021, 121: 100835

7 Goodwin AL, Calleja M, Conterio MJ, et al. Colossal positive and negative thermal expansion in the framework material $\mathrm{Ag}_{3}\left[\mathrm{Co}(\mathrm{CN})_{6}\right]$. Science, 2008, 319: 794-797

8 Chen J, Gao Q, Sanson A, et al. Tunable thermal expansion in framework materials through redox intercalation. Nat Commun, 2017, 8: 14441

9 Greve BK, Martin KL, Lee PL, et al. Pronounced negative thermal expansion from a simple structure: Cubic $\mathrm{ScF}_{3}$. J Am Chem Soc, 2010, 132: $15496-15498$

10 Wei Z, Tan L, Cai G, et al. Colossal pressure-induced softening in scandium fluoride. Phys Rev Lett, 2020, 124: 255502

11 Wang $\mathrm{C}$, Chu $\mathrm{L}, \mathrm{Yao} \mathrm{Q}$, et al. Tuning the range, magnitude, and sign of the thermal expansion in intermetallic $\mathrm{Mn}_{3}(\mathrm{Zn}, \mathrm{M})_{x} \mathrm{~N}(\mathrm{M}=\mathrm{Ag}, \mathrm{Ge})$. Phys Rev B, 2012, 85: 220103-220107

12 Azuma M, Chen WT, Seki H, et al. Colossal negative thermal expansion in $\mathrm{BiNiO}_{3}$ induced by intermetallic charge transfer. Nat Commun, 2011, 2: 347

13 McLaughlin AC, Sher F, Attfield JP. Negative lattice expansion from the superconductivity-antiferromagnetism crossover in ruthenium copper oxides. Nature, 2005, 436: 829-832

14 Schneider C, Bodesheim D, Ehrenreich MG, et al. Tuning the negative thermal expansion behavior of the metal-organic framework $\mathrm{Cu}_{3} \mathrm{BTC}_{2}$ by retrofitting. J Am Chem Soc, 2019, 141: 10504-10509

15 Wu Y, Peterson VK, Luks E, et al. Interpenetration as a mechanism for negative thermal expansion in the metal-organic framework $\mathrm{Cu}_{3}(\mathrm{btb})_{2}$ (MOF-14). Angew Chem, 2014, 126: 5275-5278

16 Zhou HL, Zhang YB, Zhang JP, et al. Supramolecular-jack-like guest in ultramicroporous crystal for exceptional thermal expansion behaviour. Nat Commun, 2015, 6: 6917

17 Evans JSO. Negative thermal expansion materials. Jpn J Appl Phys, 2000, 39: 535

18 Takenaka K. Negative thermal expansion materials: Technological key for control of thermal expansion. Sci Tech Adv Mater, 2012, 13: 013001

19 Dove MT, Fang H. Negative thermal expansion and associated anomalous physical properties: Review of the lattice dynamics theoretical foundation. Rep Prog Phys, 2016, 79: 066503

20 Mittal R, Gupta MK, Chaplot SL. Phonons and anomalous thermal expansion behaviour in crystalline solids. Prog Mater Sci, 2018, 92: $360-445$

21 Attfield JP. Mechanisms and materials for NTE. Front Chem, 2018, 6: 371

22 Takenaka K. Progress of research in negative thermal expansion materials: Paradigm shift in the control of thermal expansion. Front Chem, 2018, 6: 267

23 Liang E, Sun Q, Yuan H, et al. Negative thermal expansion: Mechanisms and materials. Front Phys, 2021, 16: 53302

24 Takenaka K, Okamoto Y, Shinoda T, et al. Colossal negative thermal expansion in reduced layered ruthenate. Nat Commun, 2017, 8: 1-7

25 Wang Q, Jackson JA, Ge Q, et al. Lightweight mechanical metamaterials with tunable negative thermal expansion. Phys Rev Lett, 2016, 117: 175901

26 Li WH, Wu SY, Yang CC, et al. Thermal contraction of Au nanoparticles. Phys Rev Lett, 2002, 89: 135504

27 Goodwin AL. The ins and outs of thermal expansion. Nat Nanotech, 2008, 3: 711-712

28 Gao Q, Wang J, Sanson A, et al. Discovering large isotropic negative thermal expansion in framework compound $\mathrm{AgB}(\mathrm{CN})_{4}$ via the concept of average atomic volume. J Am Chem Soc, 2020, 142: 6935-6939

29 Hibble SJ, Chippindale AM, Marelli E, et al. Local and average structure in zinc cyanide: Toward an understanding of the atomistic origin of negative thermal expansion. J Am Chem Soc, 2013, 135: 16478-16489

30 Goodwin AL, Chapman KW, Kepert CJ. Guest-dependent negative thermal expansion in nanoporous Prussian blue analogues $\mathrm{M}^{\mathrm{II}} \mathrm{Pt}^{\mathrm{IV}}(\mathrm{CN})_{6} \cdot x\left\{\mathrm{H}_{2} \mathrm{O}\right\}(0 \leq x \leq 2 ; \mathrm{M}=\mathrm{Zn}, \mathrm{Cd})$. J Am Chem Soc, 2005, 127: $17980-17981$

31 Duyker SG, Peterson VK, Kearley GJ, et al. Negative thermal expansion in $\mathrm{LnCo}(\mathrm{CN})_{6}(\mathrm{Ln}=\mathrm{La}, \mathrm{Pr}, \mathrm{Sm}, \mathrm{Ho}, \mathrm{Lu}, \mathrm{Y})$ : Mechanisms and compositional trends. Angew Chem Int Ed, 2016, 52: 5266-5270

32 Gao Q, Sun Y, Shi N, et al. Large isotropic negative thermal expansion in water-free Prussian blue analogues of $\mathrm{ScCo}(\mathrm{CN})_{6}$. Scripta Mater, 2020, 187: 119-124

33 Gao Q, Chen J, Sun Q, et al. Switching between giant positive and negative thermal expansions of a $\mathrm{YFe}(\mathrm{CN})_{6}$-based Prussian blue analogue induced by guest species. Angew Chem Int Ed, 2017, 56: 90239028

34 Kronenburg MJ. Atomic displacement parameters and anisotropic thermal ellipsoid lengths and angles. Acta Crystlogr Found Crystlogr, 2004, 60: 250-256

35 Sanson A. Toward an understanding of the local origin of negative thermal expansion in $\mathrm{ZrW}_{2} \mathrm{O}_{8}$ : Limits and inconsistencies of the tent and rigid unit mode models. Chem Mater, 2014, 26: 3716-3720

36 Gao Q, Shi X, Venier A, et al. Effect of $\mathrm{H}_{2} \mathrm{O}$ molecules on thermal expansion of $\mathrm{TiCo}(\mathrm{CN})_{6}$. Inorg Chem, 2020, 59: 14852-14855

37 Shi N, Sanson A, Gao Q, et al. Strong negative thermal expansion in a low-cost and facile oxide of $\mathrm{Cu}_{2} \mathrm{P}_{2} \mathrm{O}_{7}$. J Am Chem Soc, 2020, 142: 30883093

38 Dalba G, Fornasini P. EXAFS Debye-Waller factor and thermal vibra- 
tions of crystals. J Synchrotron Rad, 1997, 4: 243-255

39

Sanson A. On the switching between negative and positive thermal expansion in framework materials. Mater Res Lett, 2019, 7: 412-417

Acknowledgements This work was supported by the National Natural Science Foundation of China (22071221, 21905252, 21825102 and 11774078), the Natural Science Foundation of Henan Province (212300410086) and the Innovation Scientists and Technicians Troop Construction Projects of Henan Province (10094100510025). All calculations were supported by the National Supercomputing Center in Zhengzhou. ELETTRA Synchrotron is acknowledged for providing beamtime at the XAFS beamline (Experiment $\mathrm{n}$. 20185177). We thank Luca Olivi and Simone Pollastri for technical assistance.

Author contributions Gao Q and Chen J conceived the idea and designed the experiments. Gao Q prepared the samples and performed the measurements. Sanson A analyzed and discussed the data of the X-ray absorption fine structure experiments. Sun Q performed density functional theory (DFT) calculations. Huang $\mathrm{Q}$ assisted in the neutron powder diffraction experiments. All authors contributed to the discussions. Gao Q and Chen J wrote the manuscript with help for the revision from all coauthors.

Conflict of interest The authors declare that they have no conflict of interest.

Supplementary information Experimental details and supporting data are available in the online version of the paper.

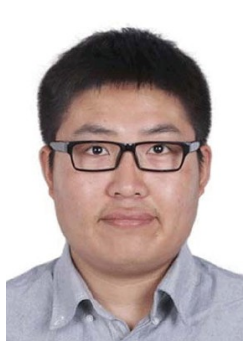

Qilong Gao is currently an associate professor at Zhengzhou university (ZZU). He received his $\mathrm{PhD}$ degree from the Department of Physical Chemistry, University of Science and Technology Beijing (USTB). He received the award of the Excellent Youth Foundation of Henan province in 2020. Currently, he concentrates on exploring the NTE mechanism, controlling thermal expansion, and finding new NTE materials, such as Prussian blue analogues, oxides, cyanides and metal-organic frameworks by means of synchrotron radiation technology.

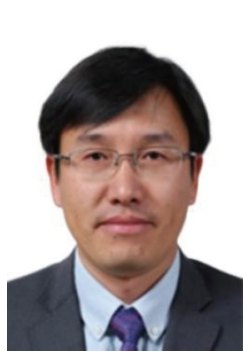

Jun Chen is currently a full professor at USTB, China. He received his $\mathrm{PhD}$ degree in Metallurgical Physical Chemistry from USTB in 2007. In 2008-2009, he was financially supported by the Alexander von Humboldt Fellowship for the research in the field of electrical ceramics at TU-Darmstadt, Germany. He visited the Structures Laboratory of the Tokyo Institute of Technology, Japan, as a foreign guest professor in 2015, and visited the Department of Physics and Astronomy of University of Padova, Italy as a visiting scientist in 2018. His current research interests include crystal structures, correlations with physical or chemical properties, and new materials design for ferroelectric, piezoelectric, magnetic, and negative thermal expansion solids.

平均原子晶格体积在预测负热膨胀材料中的作用: 以 $\operatorname{REFe}(\mathrm{CN})_{6}$ 为例

高其龙 ${ }^{*}$, 孙强 ${ }^{1}$, Alessandro Venier ${ }^{3}$, Andrea Sanson $^{3}$, Qingzhen Huang ${ }^{4}$, 贾瑜 5,1 , 梁二军 ${ }^{1}$, 陈骏 $2^{*}$

摘要 面对高精尖仪器或设备的热膨胀控制的需求, 探索新的负热膨 胀材料显得尤为重要. 本文采用“平均原子晶格体积”概念预测各向异 性新的负热膨胀材料体系，据此发现了 $R E \mathrm{Fe}(\mathrm{CN})_{6}(R E=\mathrm{La}, \mathrm{Sm}, \mathrm{Ho}$, $\mathrm{Lu}$ ) 负热膨胀材料家族. 我们采用原位中子粉末衍射 (NPD)、X射线吸 收精细结构谱(EXAFS)和第一性原理计算揭示了其负热膨胀来源于低 频声子振动模式中的 CN 原子的横向热振动, 进一步发现“平均原子晶 格体积”越大, 其对应的低频声子模式频率越低, 格林艾森常数越负, $\mathrm{CN}$ 原子的横向热振动越强. 本工作为定性预测负热膨胀材料提供了新 的方法, 对热膨胀控制与设计具有重要意义. 